\title{
Magnetic cobalt ferrite nanocomposites: Synthesis and characterization
}

\author{
J. Jeyanthi, R. Jayalakshmiand and Suganya Devi B \\ Department of Civil Engineering, \\ Government College of Technology Coimbatore, Coimbatore- 641 013, India \\ *Email: gctjeyanthi@gmail.com
}

Cobalt ferrite $\left(\mathrm{CoFe}_{2} \mathrm{O}_{4}\right)$ nanocomposite is an important class of nanocomposite metal oxides containing ferric ions enhanced with specific functionality. It possess unique physiochemical properties including excellent magnetic characteristics, high specific area, surface active sites, high chemical stability and the ease with which it can be modified or functionalized. As a result of their multifunctional properties and magnetic separable capabilities, it can be used as a potential adsorbent for the dye sequestration.

In the present communication, a low cost route for the preparation of cobalt ferrite nanocomposites containing cobalt ferrite nanoparticles stabilized in sodium alginate polymer and magnetite separately was reported. $\mathrm{CoFe}_{2} \mathrm{O}_{4}$ nanoparticles were synthesized using co - precipitation method. The surface modifications of synthesized $\mathrm{CoFe}_{2} \mathrm{O}_{4}$ nanocomposites were investigated.

The structural and morphological properties have been analyzed using X-ray diffraction and SEM micrographs. The X-ray diffraction measurements confirmed the ferrite structure formation and its stabilization with sodium alginate and magnetite respectively. The grain size of the $\mathrm{CoFe}_{2} \mathrm{O}_{4}$ nanocomposites was estimated using Scherer's formula. The SEM micrographs indicated the uniform particle size distribution in the case of Cobalt Ferrite and agglomeration was observed for both the nanocomposites (Figure 1 and Figure 2). The SEM micrograph also confirmed the nanometre range of the particle size of $\mathrm{CoFe}_{2} \mathrm{O}_{4}$ nanocomposites. The chemical composition of nanocomposites was determined by Energy dispersive Spectroscopy. The EDS results have confirmed the purity of synthesis of $\mathrm{CoFe}_{2} \mathrm{O}_{4}$ nanocomposites. The $\mathrm{N}_{2}$ absorption-desorption isotherms of the samples were measured by using the static volumetric adsorption analyzer, the pore structure of the sample was calculated by Barrett-Joyner-Halenda (BJH) academic model and the specific surface area was calculated from Brunauer-Emmett-Teller (BET) adsorption equation. With above mentioned key findings, it is proposed to carry out feasibility of dye degradation using $\mathrm{CoFe}_{2} \mathrm{O}_{4}$ nanocomposites

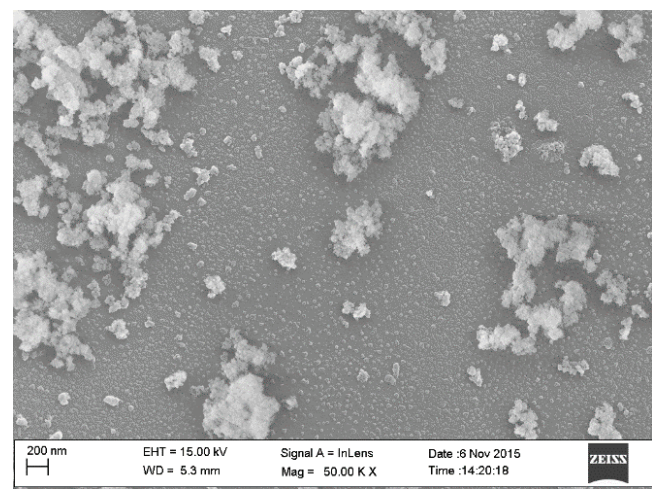

Figure 1: SEM Micrograph of Polymer matrix $\mathrm{CoFe}_{2} \mathrm{O}_{4}$ nanocomposite

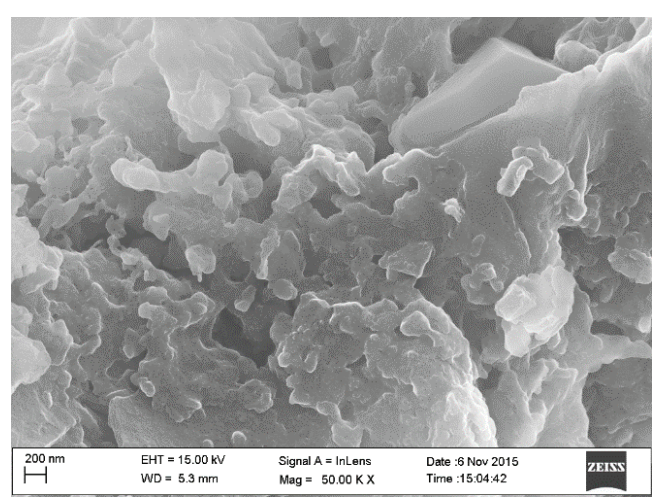

Figure 2: SEM Micrograph of Ceramic matrix $\mathrm{CoFe}_{2} \mathrm{O}_{4}$ nanocomposite

\section{References}

1. Prasad M. Tamhankar,Functionalization of Cobalt Ferrite Nanoparticles with Alginate Coating for Biocompatible Applications, Materials Sciences and Applications, (2011), 2, 1317-1321

2. Debabrata Mishra, $\mathrm{CoFe}_{2} \mathrm{O}_{4}-\mathrm{Fe}_{3} \mathrm{O}_{4}$ Magnetic Nanocomposites as Photocatalyst for the Degradation of Methyl Orange Dye, Journal of Nanotechnology, (2012), 1-6 